\title{
Horizontal canal benign paroxysmal positional vertigo: diagnosis and treatment of 37 patients
}

Vertigem posicional paroxística benigna do canal horizontal: diagnóstico e tratamento de 37 pacientes

\author{
Eliana Teixeira Maranhão ${ }^{1,2}$, Péricles Maranhão-Filho ${ }^{3}$
}

\begin{abstract}
Benign paroxysmal positional vertigo (BPPV), the most frequent cause of vertigo is associated with high morbidity in the elderly population. The most common form is linked to debris in the posterior semicircular canal. However, there has been an increasing number of reported BPPV cases involving the horizontal canals. The purpose of this article is to highlight the clinical features, diagnosis, and treatment in 37 patients with horizontal canal BPPV; twenty-six with geotropic nystagmus, and eleven with the apogeotropic form. Treatment consisted of the Gufoni manoeuver in eighteen patients (48.6\%), the barbecue $360^{\circ}$ maneuver in twelve patients (32.4\%), both manoeuvers in four patients (10.8\%), both manoeuvers plus head shaking in one patient (2.7\%), and the Gufoni maneuver plus head shaking in two patients. Cupulolithiasis patients were asked to sleep in a forced prolonged position. We obtained a complete resolution of vertigo and nystagmus in 30 patients $(81.0 \%)$ on the initial visit.
\end{abstract}

Keywords: benign paroxysmal positional vertigo, horizontal canal, dizziness, nystagmus, canalith-repositioning maneuvers.

\section{RESUMO}

Vertigem posicional paroxística benigna (VPPB) é a causa mais frequente de vertigem e promove alta morbidade na população idosa. A forma mais comum está relacionada com otoconias no canal semicircular posterior. Entretanto, nos últimos anos identifica-se cada vez mais casos de VPPB dos canais horizontais. Os principais objetivos deste artigo são destacar as características clínicas, diagnóstico e tratamentos aplicados em 37 pacientes com VPPB do canal horizontal; vinte e seis com nistagmo geotrópico, e onze com nistagmo apogeotrópico. 0 tratamento consistiu na manobra de Gufoni em dezoito pacientes (48,6\%) manobra do churrasco $360^{\circ}$ em doze pacientes $(32,4 \%)$ ambas as manobras em quatro pacientes (10,8\%) ambas as manobras mais a manobra de sacudir a cabeça (MSC) em um paciente (2,7\%), e manobra de Gufoni mais MSC em dois pacientes (2,7\%). Pacientes com cupulolitíase dormiram uma noite na posição forçada prolongada. Em 30 pacientes (81,0\%) o sucesso terapêutico ocorreu na primeira consulta.

Palavras-chave: vertigem posicional paroxística, canal horizontal, tonteira, nistagmo, manobras de reposição canalicular.

Benign paroxysmal positional vertigo (BPPV) is the most frequent type of vertigo ${ }^{1,2,3}$ with prevalence between 10.7 and 64.0 per 100,000 population, and lifetime prevalence estimated of $3.2 \%$ in females, $1.6 \%$ in males, and $2.4 \%$ overall ${ }^{1}$. BPPV generally has the highest age distribution in the sixth decade of life $e^{3,4}$, with a prevalence approaching $9 \%$ among the elderly population ${ }^{5}$. It is characterized by brief, recurrent episodes of vertigo triggered by changes in head position. Its pathophysiology, so called the "vestibular stones," concept, is either due to abnormal stimulation of the dome caused by free-floating otoliths within semicircular canals (canalolithiasis), or otoliths clinging in the dome (cupulolithiasis) ${ }^{4,6,7}$. The duration, frequency and intensity of symptoms, as well as the nystagmus phenotype, vary depending on the canal in question and the location of the debris within them. The idiopathic form is the most frequent and the average duration of episodic symptoms is about two weeks ${ }^{8}$. The right ear is usually more involved ${ }^{9}$. Eighty-six percent of affected individuals seek medical care but only $8 \%$ receive effective treatment ${ }^{8}$. When considering the frequency of affected semicircular canals, certainly for anatomical / positional reasons, BPPV of the horizontal canal (HC-BPPV) is four times less frequent than the posterior canal (PC-BPPV $)^{6,10}$, but this frequency is increasing and currently, depending on the study, the recognition of HC-BPPV ranges from $10 \%$ to $42.7 \%^{11,12}$. Although the symptoms in HC-BPPV and PC-BPPV are similar, important

${ }^{1}$ Instituto Nacional de Câncer, Departamento de Fisioterapia, Rio de Janeiro RJ, Brazil.

${ }^{2}$ American Physical Therapy Association for Vestibular Rehabilitation, Alexandria VA, USA;

${ }^{3}$ Universidade Federal do Rio de Janeiro, Hospital Clementino Fraga Filho, Departamento de Neurologia, Rio de Janeiro RJ, Brazil.

Correspondence: Eliana Teixeira Maranhão; Avenida das Américas, 1155 / 1705; 22631-000 Rio de Janeiro RJ, Brasil; E-mail: Limaranhao@gmail.com

Conflict of interest: There is no conflict of interest to declare.

Received 09 September 2014; Received in final form 10 January 2015; Accepted 30 January 2015. 
differences in the evaluation and management exist ${ }^{3,13}$. The HC-BPPV has sudden onset and usually more intense symptoms than the posterior canal variant, persisting longer than 30 seconds, and is often associated with nausea and eventually vomiting. Nevertheless, its prognosis is usually better than PC-BPPV. When untreated most HC-BPPV resolve within $16 \pm 19$ days and PC-BPPV within $39 \pm 47$ days of their onset $^{4}$. The correct diagnosis type of HC-BPPV, and treatment with appropriate maneuvers allow simple and rapid healing. Our primary objective was to achieve therapeutic success, i.e. absence of vertigo and nystagmus upon application of the supine roll test on follow-up examination, within the least amount of time and using the most practical and effective maneuvers, regardless the disease duration.

\section{METHOD}

Between June 2011 and November 2014, one hundred and ninety-three office patients with vertigo and dizziness complain were seen by the authors: 162 by ETM, and 31 by PM-F. Thirty-seven (19.1\%) aged $65.8 \pm 15.8$ years old (range 33-94), with positional vertigo and horizontal positional nystagmus were diagnosed as HC-BPPV. The time interval from the first vertigo crisis to an initial evaluation varied from one day to 40 years (mean \pm SD $54.7 \pm 127.6$ months; median: 2.0 months). Twenty-eight (75.6\%) patients were women and nine men (women-to-men ratio: 14:4.5). All presented the five items that make up the criteria for the clinical diagnosis of HC-BPPV ${ }^{3,9}: 1$ ) very short latency (few seconds) of positional vertigo episodes; 2) purely horizontal nystagmus towards the lower ear (geotropic) or upper ear (apogeotropic) induced by rotating the head while supine, with greater intensity on one side; 3) absence of spontaneous nystagmus during upright sitting position; 4) unfatigable nystagmus with repeated positioning; and 5) absence of CNS disease that can justify positional vertigo and nystagmus. All patients underwent a routine clinical neuro-otological examination including: Otoscopy, extrinsic and intrinsic ocular motility, a search for spontaneous and gaze-evoked nystagmus, horizontal and vertical smooth pursuit, saccades, head impulse test, limb ataxia, and static and dynamic balance, that was consistently normal or negative. None of them had a history of migraine or a history and examination that indicate Menière disease, vestibular neuritis or vestibular schwannoma. Patients were submitted to the provocative Pagnini-McClure test (supine roll test) $)^{14}$, with a monocular video-Frenzel goggle system (Micromedical Infrared Googles RealEyes xDVR 2.2 C). The roll test was done with the patient in the supine position with the head flexed $30^{\circ}$ and rotated $90^{\circ}$ in one direction, then returned to the starting position (head to zero degree), and the maneuver was repeated towards the opposite side. The treatment consisted in applying: Gufoni manoeuver ${ }^{15,16}$ in eighteen patients (48.6\%), the barbecue $360^{\circ}$ manoeuver
$(\mathrm{BBQ})^{17}$, in twelve patients $(32.4 \%)$, both maneuvers in four patients (10.8\%); both maneuvers plus head shaking maneuver $(\mathrm{HSM})^{18}$ in one $(2.7 \%)$; and HSM plus Gufoni maneuver in three patients. There were no specific criteria in the choice of maneuvers used in the treatment with the exception that in some patients, the Gufoni maneuver was chosen due to overweight or complaints of neck pain.

In the Gufoni maneuver to the HC-BPPV canalolithia$\operatorname{sis}^{19}$, the patient was quickly brought down on the healthy side from the sitting position with their legs hanging over the side, and after 2 minutes the head was turned about $45^{\circ}$ downward, so that the nose was on the bed. After 2 minutes in this position, the patient was returned to the upright position (Figure 1). The Gufoni maneuver for HC-BPPV cupulolithiasis, the patient head is quickly turned upward, toward the ceiling, after first being brought to the side-lying position on the affected side (Figure 2). For the BBQ the supine patient underwent a stepwise $90^{\circ}$ turns starting with the affected ear-down, followed by quick rotations to complete $360^{\circ}$. Each position was maintained for 30 to 60 seconds until the induced nystagmus dissipated. Finally, the patient was brought to a sitting position (Figure 3). For the HSM in the yaw plane $e^{18}$, the examiner vigorously moved the patient's head (fitted with infrared Frenzel goggles), from side to side $\left(30^{\circ}\right.$ to $\left.45^{\circ}\right)$ for 20 cycles with a frequency of $2-3 \mathrm{~Hz}$ for approximately 15 seconds, then stopping abruptly. It is worth mentioning that there was no concern on our part in comparing the effectiveness between different therapeutic methods. Most patients were followed by telephone call, some by office visit, up from one week to two years. All images were used in accordance with legally authorized rights.

\section{RESULTS}

From the 37 patients with HC-BPPV, twenty-six (70.2\%) showed canalolithiasis (equally distributed on either side). Eleven patients (29.7\%) presented cupulolithiasis; seven (63.6\%) on the right and four $(36.3 \%)$ on the left side.

The HSM was used in two patients with HC-BPPV cupulolithiasis who were resistant to treatment. In addition, we consistently requested our ten patients with cupulolithiasis to perform the forced prolonged position ${ }^{20}$ (sleep in lateral decubitus with the affected ear facing upwards for 12 hours) on the same evening of their visit.

Eight patients $(21.6 \%)$ were asymptomatic after just one maneuver: four after the Gufoni maneuver, and an equal number after the BBQ $360^{\circ}$ maneuver. Seventeen patients (45.9\%) were asymptomatic after two maneuvers in the first visit day: eleven patients after the Gufoni and six patients after the BBQ $360^{\circ}$. In four patients (10.8\%), both maneuvers were performed, and in three cases with HC-BPPV cupulolithiasis, additional head shaking was done. Three patients $(8.1 \%)$ transformed HC-BPPV cupulolithiasis to canalolithiasis: after head shaking 
in the yaw plane and after the BBQ $360^{\circ}$ maneuver ${ }^{17}$. Another patient had right posterior canalolithiasis BPPV that was transformed to right $\mathrm{HC}$-canalolithiasis by the BBQ $360^{\circ}$ maneuver. Seven patients $(18.9 \%)$ had to return after an interval of two or three days to reapply the maneuvers; two returned four times.

Due to the clarity of direction and intensity of nystagmus observed with Frenzel glasses, in none of our patients required the use of the Bow and Lean test ${ }^{21}$ in order to decide the affected side.

The BPPV was mostly idiopathic but in two patients the vertigo crises began after cranial trauma. Seventeen patients
(45.9\%) had had lengthy unsuccessful treatments with anti-vertigo medications drugs before maneuvers were applied.

Five patients, despite many years of disease duration and several vertigo episodes, were asymptomatic after completing treatment with the maneuvers as determined by the absence of vertigo and nystagmus in the supine roll test. The number of manoeuver repetitions and required sessions are summarized in the Table. The therapeutic success achieved after maneuvers (patient's without vertigo and nystagmus in the supine roll test) was $100 \%$, of which $80.0 \%$ was achieved during the first office visit.
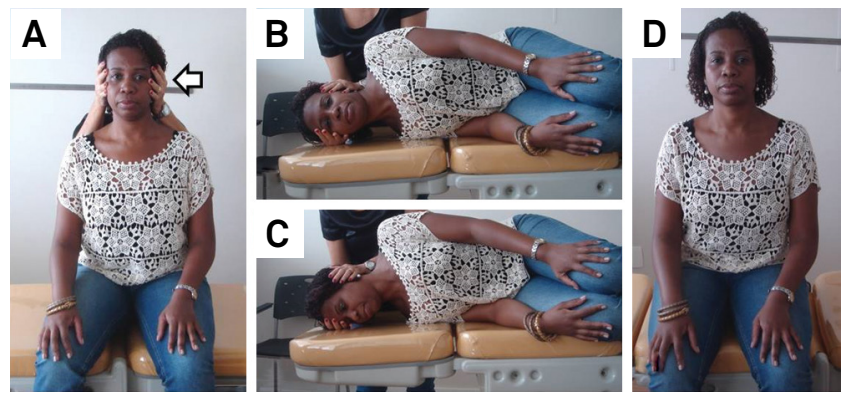

Figure 1. Gufoni's maneuver for HC-BPPV canalolithiasis treatment. Patient sits upright (arrow indicates the affected side) (A), then is quickly laid down sideways with the affected ear pointed upwards, remaining there for two minutes (B). The patient's head is then quickly rotated $45^{\circ}$ towards the ground and kept there for two minutes (C), followed by a slow return to the sitting position (D). This maneuver has also been referred to as the Appiani maneuver for HC-BPPV canalithiasis treatment (Photo authorized by Rev.Bras. Neurol ${ }^{19}$ ).
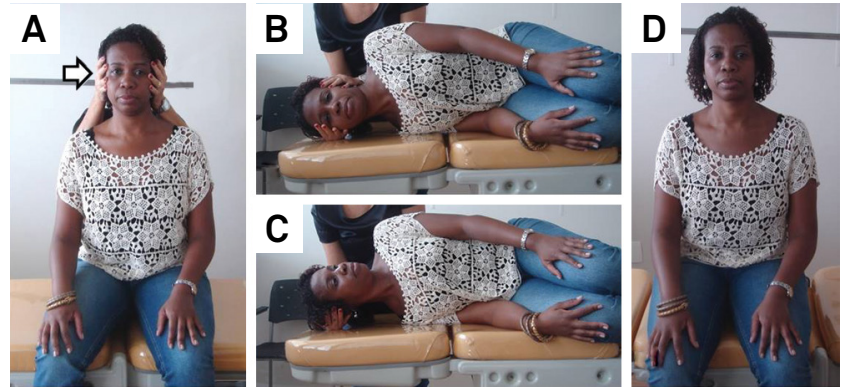

Figure 2. Gufoni's maneuver to treat HC-BPPV cupulolithiasis. Patient sits upright (arrow indicates the affected side) (A), then is quickly laid down sideways with the affected ear pointed downwards (B). The patient's head is then quickly rotated $45^{\circ}$ toward the ceiling and kept there for two minutes (C), followed by a slow return to the sitting position (D). This maneuver has also been referred to as the Casani maneuver for HC-BPPV cupulolithiasis treatment.
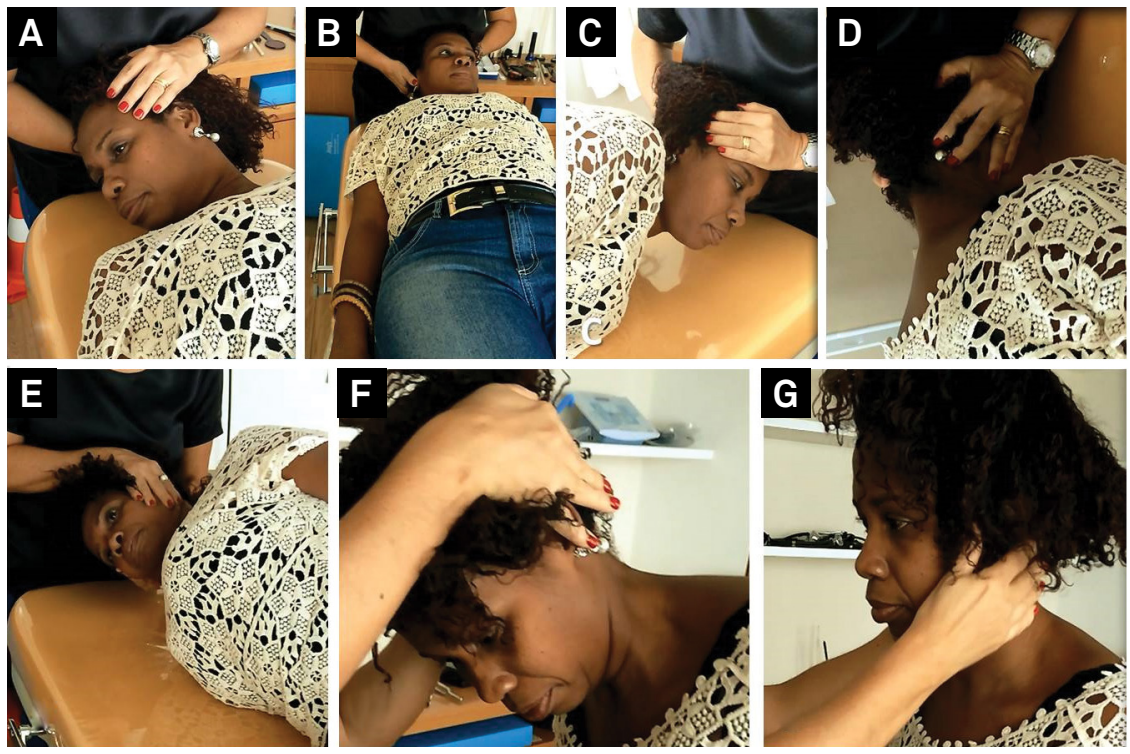

Figure 3. Barbecue $360^{\circ}$ maneuver (supine roll maneuver) for treatment of right HC-BPPV canalolithiasis. Patient's head is rolled $360^{\circ}$ in quick $90^{\circ}$ increments (with one minute intervals). The motion is started with a head rotation from the supine position to the unaffected side ( $A$ and B). Subsequently, the patient is rolled over to the prone position while the head is held in the same position before it is turned rapidly to the nose-to-ground position ( $\mathrm{C}$ and $\mathrm{D}$ ). Then, the head is rotated vigorously to the opposite lateral position with the affected ear once again pointed towards the ceiling (E). Finally, the patient is sat upright with the chin tucked (F) and the head is extended (G) 
Table. Demographics and some comments of thirty-seven patients with Horizontal Canal Benign Paroxysmal Positional Vertigo (HC-BPPV).

\begin{tabular}{|c|c|c|c|c|c|c|}
\hline No. & Gender & Age & Type & Duration & Manouver (count) & Comments \\
\hline 1 & $\mathrm{~F}$ & 50 & $\mathrm{RHC}$ & $1 d$ & Barbecue $360^{\circ}(1)$ & $1^{\circ}$ BPPV 7 years ago \\
\hline 2 & $\mathrm{~F}$ & 63 & LHC & $3 \mathrm{~m}$ & Barbecue $360^{\circ}(2)$ & 3m after BPPV LPC \\
\hline 3 & $\mathrm{~F}$ & 63 & $\mathrm{RHCc}$ & $3 \mathrm{~m}$ & $\operatorname{Barb}(1)+H S+$ Guf (1) & Diag.: cervical vertigo \\
\hline 4 & M & 62 & $\mathrm{RHCc}$ & $1 \mathrm{~m}$ & Gufoni (2 sessions) & Treatment with drugs \\
\hline 5 & $\mathrm{~F}$ & 38 & $\mathrm{RHC}$ & $6 \mathrm{~m}$ & Gufoni (2 sessions) & Diag.: emotional stress \\
\hline 6 & $\mathrm{~F}$ & 33 & $\mathrm{RHC}$ & $4 \mathrm{~m}$ & Barbecue $360^{\circ}(1)$ & Post cranial trauma \\
\hline 7 & $\mathrm{~F}$ & 50 & LHC & $1 \mathrm{~m}$ & Barbecue $360^{\circ}(2)$ & Treatment with drugs \\
\hline 8 & $\mathrm{~F}$ & 87 & $\mathrm{RHC}$ & $20 y^{\star}$ & Gufoni (2) & Treatment with drugs \\
\hline 9 & $\mathrm{~F}$ & 83 & $\mathrm{RHCc}$ & $6 \mathrm{~m}$ & Gufoni (2) & Treatment with drugs \\
\hline 10 & $\mathrm{~F}$ & 64 & $\mathrm{RHCC}$ & $6 \mathrm{~m}$ & HS + Guf (3 sessions) & $1^{\circ}$ BPPV RPC $6 \mathrm{~m}$ ago \\
\hline 11 & $\mathrm{~F}$ & 59 & $\mathrm{RHC}$ & $11 / 2 m$ & Barbecue $360^{\circ}(1)$ & Head / Neck câncer \\
\hline 12 & $\mathrm{~F}$ & 64 & $\mathrm{RHC}$ & $2 w$ & Gufoni (1) & Treatment with drugs \\
\hline 13 & M & 79 & LHC & $2 \mathrm{~m}$ & Gufoni (2) & Parkinsonism \\
\hline 14 & $\mathrm{~F}$ & 60 & LHC & $6 \mathrm{~m}$ & Gufoni (1) & Treatment with drugs \\
\hline 15 & $\mathrm{~F}$ & 53 & LHC & $1 w$ & Gufoni (2) & Multiple sclerosis \\
\hline 16 & $\mathrm{~F}$ & 71 & LHC & $1 \mathrm{y}$ & Guf + Barb ( 4 sessions) & Diag.: dementia \\
\hline 17 & $\mathrm{~F}$ & 69 & LHC & $1 \mathrm{~m}$ & Guf (1) + Barb (1) & Treatment with drugs \\
\hline 18 & $\mathrm{~F}$ & 37 & LHC & $2 w$ & Barbecue $360^{\circ}(1)$ & Treatment with drugs \\
\hline 19 & M & 60 & $\mathrm{RHCC}$ & $6 y$ & Gufoni (2) & $1{ }^{\circ}$ BPPV 6 years ago \\
\hline 20 & M & 82 & LHC & $2 m$ & Barbecue $360^{\circ}(2)$ & LPC tranformed \\
\hline 21 & M & 77 & $\mathrm{RHC}$ & $3 y$ & Gufoni (1) & Post cranial trauma \\
\hline 22 & $\mathrm{~F}$ & 41 & $\mathrm{RHC}$ & $2 m$ & Barbecue $360^{\circ}(2)$ & Treatment with drugs \\
\hline 23 & $\mathrm{~F}$ & 82 & $\mathrm{RHC}$ & $20 y^{\star}$ & Barb: (4 sessions) & BPPV multi canals \\
\hline 24 & $\mathrm{~F}$ & 83 & $\mathrm{RHCC}$ & $2 y$ & Gufoni (1) & Treatment with drugs \\
\hline 25 & F & 63 & $\mathrm{LHC}$ & $2 w$ & Barbecue $360^{\circ}(2)$ & Treatment with drugs \\
\hline 26 & $\mathrm{~F}$ & 63 & LHC & $2 w$ & Barbecue $360^{\circ}(2)$ & LHCc transformed \\
\hline 27 & $\mathrm{~F}$ & 59 & $\mathrm{RHC}$ & $11 / 2 y$ & Barbecue $360^{\circ}(2)$ & RPC transformed \\
\hline 28 & $\mathrm{~F}$ & 50 & LHC & $7 d$ & Guf (1) + Barb (1) & Treatment with drugs \\
\hline 29 & $\mathrm{~F}$ & 86 & $\mathrm{RHC}$ & $40 y^{\star}$ & Guf + Guf ( 2 sessions) & Treatment with drugs \\
\hline 30 & $\mathrm{~F}$ & 87 & LHC & $40 y^{\star}$ & Gufoni (2) & Treatment with drugs \\
\hline 31 & $\mathrm{~F}$ & 86 & $\mathrm{RHC}$ & $6 \mathrm{~d}$ & Gufoni (2) & Treatment with drugs \\
\hline 32 & $\mathrm{~F}$ & 75 & $\mathrm{RHC}$ & $15 d$ & Gufoni (2) & Treatment with drugs \\
\hline 33 & M & 72 & LHCc & $1 \mathrm{y}$ & Gufoni (2) & Irritable bowel \\
\hline 34 & M & 63 & $\mathrm{LHCc}$ & $2 d$ & Gufoni (2) & $1^{\circ}$ BPPV 3 years ago \\
\hline 35 & M & 83 & LHCc & $2 \mathrm{~m}$ & Gufoni (2) & $2 \mathrm{w}$ after BPPV RPC \\
\hline 36 & $\mathrm{~F}$ & 44 & LHCc & $4 d$ & Guf (1) + Barb (1) & Transformed into LHC \\
\hline 37 & M & 94 & $\mathrm{RHCc}$ & $30 y^{*}$ & $\begin{array}{c}\text { Guf (2) + HS + Guf (2) } \\
\text { (2 sessions) }\end{array}$ & Treatment with drugs \\
\hline
\end{tabular}

BPPV: benign positional paroxysm vertigo; F: female; M: male; RHC: right horizontal canal; LHC left horizontal canal; RPC: right posterior canal; RHCc: right horizontal canal cupulolithiasis; LHCc: left horizontal canal cupulolithiasis; d: days; w: week; m: months; y: years; Barb: barbecue $360^{\circ}$; Guf: Gufoni; HS: head shaking; Diag.: diagnostic; Drugs: anti-vertiginous; Sessions: day visit; *Frequently recurrent episodes without prolonged periods free of symptoms.

\section{DISCUSSION}

For many years it was believed that BPPV developed only by compromise of the posterior semicircular canal ${ }^{4}$. However, this concept was changed when in 1985 Mc-Clure described seven cases with pure geotropic nystagmus (nystagmus beating towards the ground) during the Dix-Hallpike maneuver in patients without any evidence of CNS lesions ${ }^{14}$. In 1995 the apogeotropic type of BPPV was also reported, in which the nystagmus beats towards the ceiling during lateral head turning in the supine position, corresponding to cupulolithiasis of the horizontal canal ${ }^{22}$. In the following years further HC-BPPV case publications have emerged ${ }^{11,20,21,23,24}$.
In the HC-BPPV two types of nystagmus are present: geotropic and apogeotropic, depending on canalolithiasis or $\mathrm{cu}-$ pulolithiasis respectively. The side with greater intensity nystagmus dictates the affected side in the former, while the reverse is true for the later. Treatment is designed to move the offending crystals from the semicircular canals into the utricle. Therefore, determination of the involved side by nystagmus lateralization and intensity is very important for the proper treatment of HC-BPPV.

Kim JS et al. ${ }^{9}$ held a comparative study between the Gufoni maneuver and BBQ $\left(270^{\circ}\right)$ maneuver in 170 consecutive patients with geotropic HC-BPPV. They demonstrated that booth were effective treatment methods 
[38 of 55 (69.1\%) for BBQ rotation, and 39 of 64 (60.9\%) for the Gufoni maneuver], even when applied only twice in the initial visit day. In our study 17 of 36 (47.2\%) HCBPPV patients responded to the Gufoni maneuver and 11 of 36 patients $(30.5 \%)$ responded to the BBQ $360^{\circ}$ in the their first visit; eight of these responded to a single maneuver. Beyond the Gufoni and BBQ maneuvers, two other procedures were used in our cupulolithiasis patients; the HSM (in three patients) and forced prolonged position ${ }^{20}$. Kim J-S et al. ${ }^{12}$ showed in 157 patients that both the Gufoni and HSM maneuvers were equally effective in the treatment of HC-BPPV cupulolithiasis, with success rates of $73.1 \%$ and $62.3 \%$, respectively. Oh Sy, et al..$^{25}$ compared the efficacy of HSM versus the modified Semont maneuver in 103 patients, concluding that the former is more effective (37.3\% versus $17.3 \%)$ in the resolution of vertigo/nystagmus. The BBQ $360^{\circ}$ maneuver around the yaw axis toward the unaffected ear is a popular and consecrated method of treatment for geotropic HC-BPPV ${ }^{17}$. We utilized this maneuver in isolation in eleven patients, and in association with the Gufoni maneuver in four patients after re-testing.

A comparative study between the Gufoni maneuver and barbecue-plus-forced-position maneuvers showed a higher success rate for the former (93\% versus $81 \%$ ), in addition to faster problem resolution and excellent immediate outcome with just one maneuverer ${ }^{26,27}$. In a prospective observational study involving 60 patients, the effectiveness of forced prolonged position did not differ significantly from that of Gufoni maneuver; both were more effective than the barbecue rotation after a single application (with success rates of $76 \%$ and $89 \%$, respectively, vs. $38 \%)^{20}$. All our cupulolithiasis patients were asked to sleep only one night in forced prolonged position. Since all patients performed this procedure, we can't affirm that this has influenced results and contribute to therapeutic success.

In addition to its higher success rate, the Gufoni maneuver ${ }^{15}$ is not only less time consuming ${ }^{12}$ but also easier to perform than the $\mathrm{BBQ} 360^{\circ}$ maneuver in obese or elderly persons and in patients with cervical pain and stiffness ${ }^{9,17}$. It is worth mentioning that one third of our patients were over 70 years old.

Skull trauma accidents, vestibular neuritis, otitis media, and Menière's disease are known BPPV precursors ${ }^{1,2,6,10,28}$. In our cases, BPPV was mostly idiopathic but in two patients the vertigo began after cranial trauma. The first had BPPV for four months after an occipital head trauma. Eighteen patients (48.6\%) were unsuccessfully treated with anti-vertiginous drugs; some of them for many years before the maneuvers approach was applied. Some patients (13.5\%) had co-morbidities such as parkinsonism, multiple sclerosis, dementia, irritable bowel, and tongue tumors, apparently without relationship to the pathogenesis of BPPV, except for the fact that some of these patients were bedridden for extended periods of time. Unfortunately one of ours patient with HC-BPPV was wrongfully diagnosed with anxiety attacks and referred for psychiatric treatment.

BPPV has a recurrence rate of approximately $15 \%$ per year. However, one cross-sectional study showed a recurrence rate in $56 \%$ of affected individuals within one year ${ }^{2}$. Cases of recurrence mostly happened (80\%) within the first year after treatment, irrespective of the maneuvers applied ${ }^{29}$. Five of our patients (13.5\%) had BPPV recurrence, of which two had PC-BPPV episodes three and six months prior to their medical visits, respectively. The other three patients had BPPV crises that occurred three, six and seven years prior to their medical visits (retrospective diagnosis).

Positional horizontal nystagmus can be observed in some central and peripheral vestibulopathies ${ }^{30}$. Important for this differentiation from BPPV are the clinical history, the neuro-otologic examination results, and the therapeutic success - with long time absence of nystagmus and vertigo - after the employment of adequate vestibular maneuvers for BPPV cases.

In summary, considering that human beings possess three semicircular canals on each side of the head, each canal with its respective dome and anterior short arm, there are eighteen different possible BPPV localizations; not to mention the possibility of multiple simultaneous canal involvement. Although PC-BPPV is the most common type, HC-BPPV is being increasingly diagnosed. The use of the Gufoni and BBQ $360^{\circ}$ maneuvers proved quite effective (> 80\% resolution in a first visit day) for both; canalolithiasis and cupulolithiasis HC-BPPV treatment. In our view, the winsomeness of establishing a vestibular lithiasis diagnosis derives from four straightforward facts. First, the diagnosis may emerge by simply using bare hands. Second, treatment is masterly performed with elegant and efficacious bedside maneuvers without the need of complex machinery. Third, anti-vertigo medication or supplementary tests are not required. Last but not least, the extraordinarily disabling symptoms are almost always resolved forthwith.

\section{ACKNOWLEDGEMENT}

The authors are in debit with Péricles Maranhão Neto and Dr. Renato Gonik for their technical support and suggestions. 
1. Kim J-S., Zee DS. Benign paroxysmal positional vertigo. N Engl J Med. 2014;370(12):1138-47. http://dx.doi.org/10.1056/NEJMcp1309481

2. Marom T, Oron Y, Watad W, Levy D, Roth Y. Revisiting benign paroxysmal positional vertigo pathophysiology. Am J Otolaryngol. 2009:30(4):250-5.

3. Francesco R, Francesco D, Salvatore G, Gautham K, Rosalia G, Riccardo S. Management of benign paroxysmal positional vertigo of lateral semicircular canal by Gufoni's manoeuvre. Am J Otolaryngol. 2009;30(2):106-11. http://dx.doi.org/10.1016/j.amjoto.2008.03.001

4. Lee SH, Kim JS. Benign paroxysmal positional vertigo. J Clin Neurol. 2010;6(2):51-63. http://dx.doi.org/10.3988/jcn.2010.6.2.51

5. Kaski D., Bronstein AM. Epley and beyond: an update on treating positional vertigo. Pract Neurol. 2014;14(4):210-21. http://dx.doi.org/10.1136/practneurol-2013-000690

6. Baloh RW, Honrubia V. Clinical neurophysiology of the vestibular system. 3rd ed. Oxford: Oxford University Press; 2001.

7. Kim SH, Jo SW, Chung WK, Byeon HK, Lee WS. A cupulolith repositioning maneuver in the treatment of horizontal canal cupulolithiasis. Auris Nasus Larynx. 2012;39(2):163-8. http://dx.doi.org/10.1016/j.anl.2011.03.008

8. Brevern M, Radtke A, Lezius F, Feldmann M, Ziele T, Lempert T et al. Epidemiology of benign paroxysmal positional vertigo: a population based study.J Neurol Neurosurg Psychiatry. 2007;78(7):710-5. http://dx.doi.org/10.1136/jnnp.2006.100420

9. Kim JS, Oh SY, Lee SH, Kang JH, Kim DU, Jeong SH et al. Randomized clinical trial for geotropic horizontal canal benign paroxysmal positional vertigo. Neurology. 2012;79(7):700-7. http://dx.doi.org/10.1212/WNL.0b013e3182648b8b

10. Leigh RJ, Zee DS. The neurology of eye movements. 4th ed. Oxford: Oxford University Press, 2006.

11. De la Meilleure G, Dehaene I, Depondt M, Damman W, Crevits $L$, Vanhooren G. Benign paroxysmal positional vertigo of the horizontal canal. J Neurol Neurosurg Psychiatry. 1996;60(1):68-71. http://dx.doi.org/10.1136/jnnp.60.1.68

12. Kim JS, Oh SY, Lee SH, Kang JH, Kim DU, Jeong SH et al. Randomized clinical trial for apogeotropic horizontal canal benign paroxysmal positional vertigo. Neurology. 2012;78(3):159-66. http://dx.doi.org/10.1212/WNL.0b013e31823fcd26

13. Kerber KA, Helmchen C. Benign paroxysmal positional vertigo; new opportunities but still old challenges [editorial]. Neurology. 2012;78(3):154-6. http://dx.doi.org/10.1212/WNL.0b013e318241f2a2

14. McClure JA. Horizontal canal BPV.J Otolaryngol. 1985;14(1):30-5.

15. Gufoni M, Mastrosimone L. Trattamento con manovra di riposizionamento per la canalolitiasi orizzontale. Acta Otorhinolaryngol Ital. 1998;18(6):363-7.

16. Appiani GC, Catania G, Gagliardi M, Cuiuli G. Repositioning maneuver for the treatment of the apogeotropic variant of horizontal canal benign paroxysmal positional vertigo. Otol Neurotol. 2005;26(2):257-60.
17. Baloh RW. Horizontal benign positional vertigo (correspondence reply). Neurology. 1994;44(11):2214. http://dx.doi.org/10.1212/WNL.44.11.2214

18. Maranhão ET, Maranhão Filho P. Manobra de sacudir a cabeça para diagnóstico e tratamento da disfunção vestibular. Rev Bras Neurol. 2013;49(2):52-6.

19. Maranhão ET., Maranhão Filho P. Tratamento da vertigem posicional paroxística benigna do canal horizontal (VPPB-CH): manobra de Gufoni. Rev Bras Neurol. 2014;50(2):23-5.

20. Vannucchi P, Giannoni B, Pagnini P. Treatment of horizontal semicircular canal benign paroxysmal positional vertigo. J Vestib Res. 1997;7(1):1-6. http://dx.doi.org/10.1016/S0957-4271(96)00112-7

21. Choung YH, Shin YR, Kahng H, Park K, Choi SJ. 'Bow and lean test' to determine the affected ear of horizontal canal benign paroxysmal positional vertigo. Laryngoscope. 2006;116(10):1776-81. http://dx.doi.org/10.1097/01.mlg.0000231291.44818.be

22. Baloh RW, Yue Q, Jacobson KM, Honrubia V. Persistent direction changing positional nystagmus: another variant of benign positional nystagmus? Neurology. 1995;45(7):1297-301. http://dx.doi.org/10.1212/WNL.45.7.1297

23. Strupp M, Brandt T, Steddin S. Horizontal canal benign paroxysmal positioning vertigo: reversible ipsilateral caloric hypoexcitability caused by canalolithiasis? Neurology. 1995;45(11):2072-6. http://dx.doi.org/10.1212/WNL.45.11.2072

24. Casani AP, Vannucci G, Fattori B, Berrettini S. The treatment of horizontal canal positional vertigo: our experience in 66 cases. Laryngoscope. 2002;112(1):172-8. http://dx.doi.org/10.1097/00005537-200201000-00030

25. Oh Sy, Kim JS, Jeong SH, Oh YM, Choi KD, Kim, BK et al. Treatment of apogeotropic benign positional vertigo: comparison of therapeutic head-shaking and modified Semont maneuver. J Neurol. 2009;256(8):1330-6. http://dx.doi.org/10.1007/s00415-009-5122-6

26. Casani AP, Gufoni M, Sellari-Franceschini S, Dallan I. Efficacia terapeutica delle manovre liberatorie per la VPPB del canale semicircolare orizzontale: due metodi di trattamento a confronto. Otoneurologia. 2001;(35):6-14.

27. Casani AP, Nacci A, Dallan I, Panicucci E, Gufoni M, Sellari-Franceschin S. Horizontal semicircular canal benign paroxysmal positional vertigo: effectiveness of two different methods of treatment. Audiol Neurotol. 2011;16(3):175-84. http://dx.doi.org/10.1159/000317113

28. Herdman SJ Clendaniel RA. Vestibular rehabilitation. 4th ed. Philadelphia: F. A. Davis; 2014.

29. Brandt T, Huppert D, Hecht J, Karch C, Strupp M. Benign paroxysmal positioning vertigo: a long-term follow up (6-17 years) of 125 patients. Acta Otolaryngol. 2006;126(2):160-3. http://dx.doi.org/10.1080/00016480500280140

30. Lechner C, Taylor RL, Todd C, Macdougall H, Yavor R, Halmagyi GM et al. Causes and characteristics of horizontal positional nystagmus J Neurol. 2014;261(5):1009-17. http://dx.doi.org/10.1007/s00415-013-7223-5 